\title{
Evaluation Criteria for Communications-Related Corrective Action Plans
}

Manuscript Completed: December 1996

Date Published: February 1997

Division of Reactor Controls and Human Factors

Office of Nuclear Reactor Regulation

\author{
Division of Systems Technology \\ Office of Nuclear Regulatory Research \\ U.S. Nuclear Regulatory Commission \\ Washington, DC 20555-0001
}
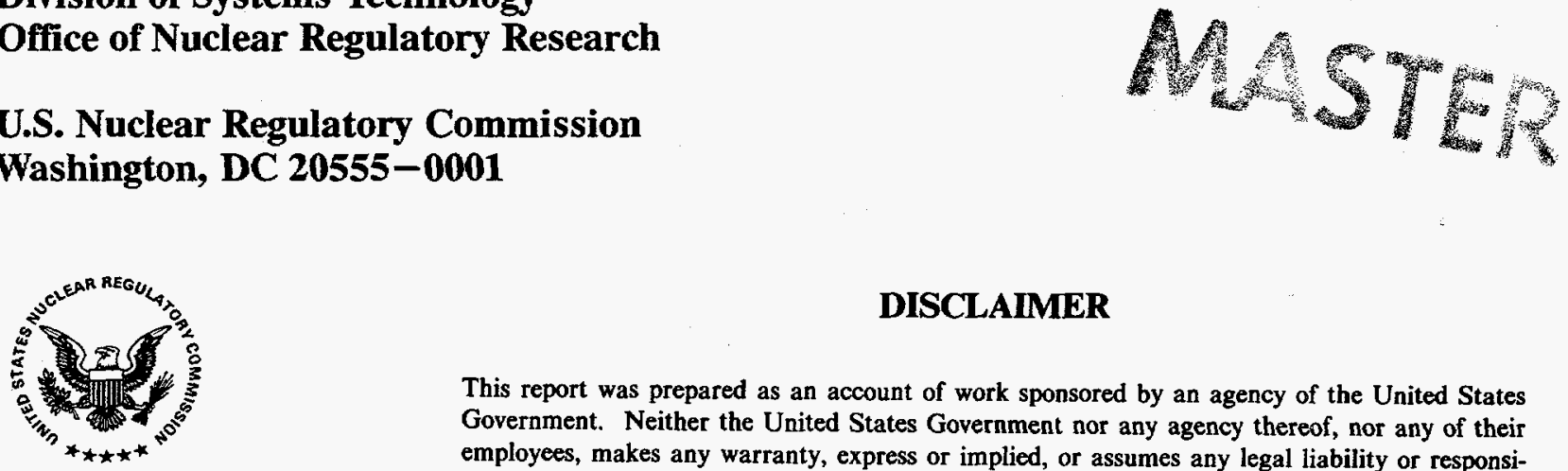

\section{DISCLAIMER}

This report was prepared as an account of work sponsored by an agency of the United States Government. Neither the United States Government nor any agency thereof, nor any of their employees, makes any warranty, express or implied, or assumes any legal liability or responsibility for the accuracy, completeness, or usefulness of any information, apparatus, product, or process disclosed, or represents that its use would not infringe privately owned rights. Reference herein to any specific commercial product, process, or service by trade name, trademark, manufacturer, or otherwise does not necessarily constitute or imply its endorsement, recommendation, or favoring by the United States Government or any agency thereof. The views and opinions of authors expressed herein do not necessarily state or reflect those of the United States Government or any agency thereof. 


\section{AVAILABILITY NOTICE}

\section{Availability of Reference Materials Cited in NRC Publications}

Most documents cited in NRC publications will be available from one of the following sources:

1. The NRC Public Document Room, 2120 L Street, NW., Lower Level, Washington, DC 20555-0001

2. The Superintendent of Documents, U.S. Government Printing Office, P. O. Box 37082 , Washington, DC 20402-9328

3. The National Technical Information Service, Springfield, VA 22161-0002

Although the listing that follows represents the majority of documents cited in NRC publications, it is not intended to be exhaustive.

Referenced documents available for inspection and copying for a fee from the NRC Public Document Room include NRC correspondence and internal NRC memoranda; NRC bulletins, circulars, information notices, inspection and investigation notices; licensee event reports; vendor reports and correspondence; Commission papers; and applicant and licensee documents and correspondence.

The following documents in the NUREG series are available for purchase from the Government Printing Office: formal NRC staff and contractor reports, NRC-sponsored conference proceedings, international agreement reports, grantee reports, and NRC booklets and brochures. Also available are regulatory guides, NRC regulations in the Code of Federal Regulations, and Nuclear Regulatory Commission Issuances.

Documents available from the National Technical Information Service include NUREG-series reports and technical reports prepared by other Federal agencies and reports prepared by the Atomic Energy Commission, forerunner agency to the Nuclear Regulatory Commission.

Documents available from public and special technical libraries include all open literature items, such as books, journal articles, and transactions. Federal Register notices, Federal and State legislation, and congressional reports can usually be obtained from these libraries.

Documents such as theses, dissertations, foreign reports and translations, and non-NRC conference proceedings are available for purchase from the organization sponsoring the publication cited.

Single copies of NRC draft reports are available free, to the extent of supply, upon written request to the Office of Administration, Distribution and Mail Services Section, U.S. Nuclear Regulatory Commission, Washington DC 20555-0001.

Copies of industry codes and standards used in a substantive manner in the NRC regulatory process are maintained at the NRC Library, Two White Flint North, 11545 Rockville Pike, Rockville, MD 20852-2738, for use by the public. Codes and standards are usually copyrighted and may be purchased from the originating organization or, if they are American National Standards, from the American National Standards Institute, 1430 Broadway, New York, NY 10018-3308. 


\section{DISCLAMMER}

Portions of this document may be illegible in electronic image products. Images are produced from the best available original document. 


\begin{abstract}
This document provides guidance and criteria for U.S. Nuclear Regulatory Commission (NRC) personnel to use in evaluating corrective action plans for nuclear power plant communications. The document begins by describing the purpose, scope, and applicability of the evaluation criteria. Next, it presents background information concerning the communication process, root causes of communication errors, and development and implementation of corrective actions. The document then defines specific criteria for evaluating the effectiveness of the corrective action plan, interview protocols, and an observation protocol related to communication processes. This document is intended only as guidance. It is not intended to have the effect of a regulation, and it does not establish any binding requirements or interpretations of NRC regulations.
\end{abstract}




\section{CONTENTS}

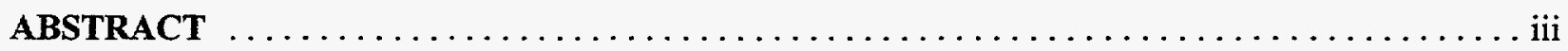

ACKNOWLEDGEMENT $\ldots \ldots \ldots \ldots \ldots \ldots \ldots \ldots \ldots \ldots \ldots \ldots \ldots \ldots \ldots \ldots \ldots \ldots$ vii

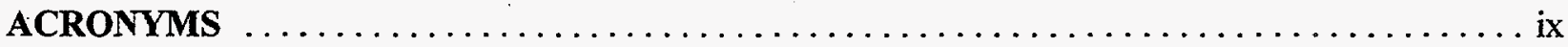

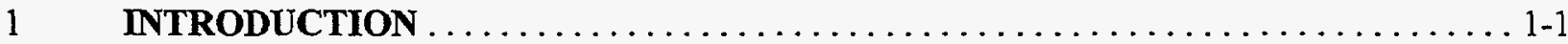

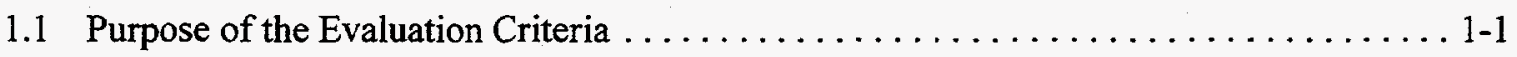

1.2 Scope and Applicability of the Evaluation Criteria $\ldots \ldots \ldots \ldots \ldots \ldots \ldots \ldots \ldots \ldots$

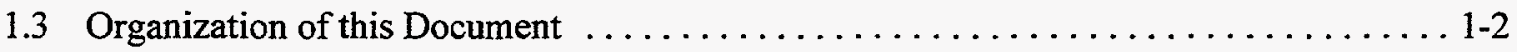

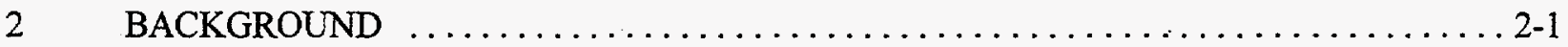

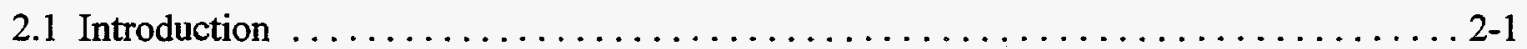

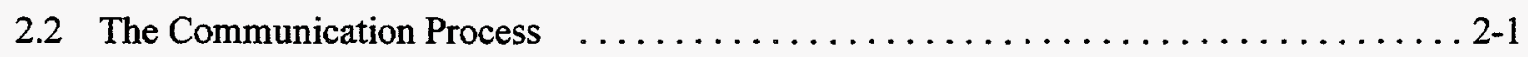

2.3 Errors in the Communication Process $\ldots \ldots \ldots \ldots \ldots \ldots \ldots \ldots \ldots \ldots \ldots \ldots \ldots \ldots \ldots \ldots \ldots .2$

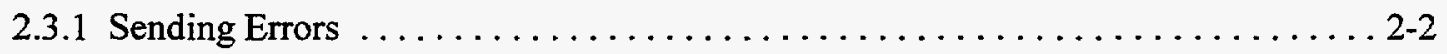

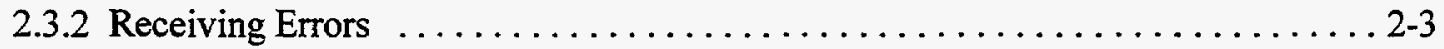

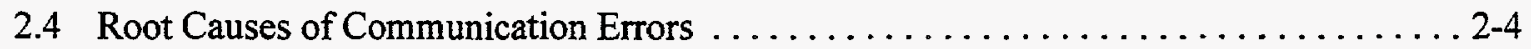

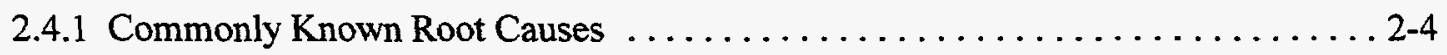

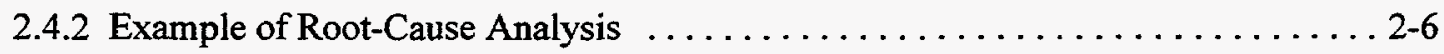

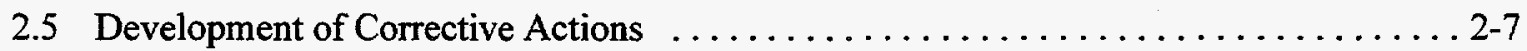

2.6 Corrective Action Implementation and Effectiveness $\ldots \ldots \ldots \ldots \ldots \ldots \ldots \ldots .7$

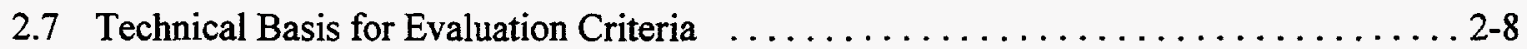

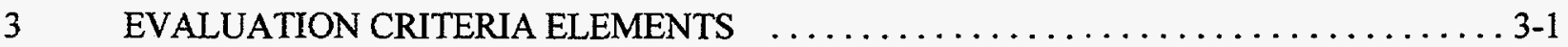

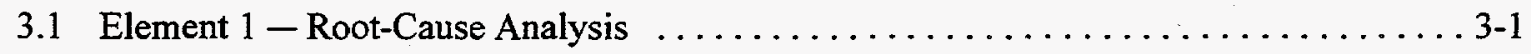

3.2 Element 2 - Development of Corrective Actions $\ldots \ldots \ldots \ldots \ldots \ldots \ldots \ldots \ldots \ldots \ldots$ 
3.3 Element 3-Corrective Action Implementation and Effectiveness

4.1 Root-Cause Analysis Interview Protocol

4.2 Development of Corrective Action Interview Protocol

4.3 Corrective Action Implementation and Effectiveness Interview Protocol $\ldots \ldots \ldots .4-6$

5.1 Communication of Equipment Changes to Shift Personnel

5.2 Timely Communication to Shift Management Concerning Abnormal Conditions and Panel Manipulations

5.3 Use of Uniform Communication Techniques $5-4$

5.4 Maintenance of Accurate and Timely Logs that Reflect Plant Activities and Status.

6.1 Element 1-Root-Cause Analysis

6.2 Element 2 - Development of Corrective Actions 6-3

6.3 Element 3-Corrective Action Implementation and Effectiveness $6-5$ 


\section{ACKNOWLEDGEMENT}

The research on which this document is based was conducted by Valerie Barnes and Christopher Moore of Performance, Safety, and Health Associates; Randall Mumaw of Westinghouse Science and Engineering Center; and Joseph DeBor of Science and Engineering Associates, Inc.

The work involved in translating the technical information from the research into evaluation criteria for U.S. Nuclear Regulatory Commission (NRC) personnel to use in evaluating corrective action plans for nuclear power plant communications was performed by Clare Goodman and Garmon West of the NRC's Office of Nuclear Reactor Regulation (NRR) and Isabelle Schoenfeld of the NRC's Office of Nuclear Regulatory Research (RES).

The authors wish to acknowledge the important contribution of three subject matter experts who provided feedback on the technical research approach and findings and commented on key project issues. Those experts are Judith Orasanu, Operations Human Factors Branch, NASA-AMES Research Center; Ted Mallory, Director of Flight Training Development, Northwest Airlines; and Victor Peters, independent consultant to the nuclear power industry on work control and self-assessment processes. 



\section{ACRONYMS}

AO auxiliary operator

CFR Code of Federal Regulations

HPIP Human Performance Investigation Process

LCO limiting condition for operation

LER licensee event report

MORT Management Organization and Risk Tree

NRC U.S. Nuclear Regulatory Commission

NRR Office of Nuclear Reactor Regulation

NPP nuclear power plant

PA public address

RES Office of Nuclear Regulatory Research 


\section{INTRODUCTION}

This document is designed to be used by U.S. Nuclear Regulatory Commission (NRC) personnel who evaluate the root causes of communication errors at nuclear power plants (NPPs), as well as corrective action plans for improving communications as part of event and incident investigation or followup. The purpose of these evaluations is to verify compliance with the applicable requirements of Title 10 of the Code of Federal Regulations (10 CFR) Part 50, Appendix B, Criterion XVI, "Corrective Action."

\subsection{Purpose of the Evaluation Criteria}

NRC personnel conduct analyses of licensee event reports (LERs) and event investigations related to human performance at NPPs. These analyses have shown that a significant number of events involve problems with written and verbal communication among plant personnel. In fact, communication is cited as a contributing factor in as many as 35 percent of LERs involving human performance problems.

Corrective action plans to address these human performance problems vary in scope. Some are broad in scope and address general plant improvement. They may involve all or a large proportion of the work groups at the site and, perhaps, corporate headquarters as well. Their purpose is to effect significant changes in work and managerial processes in order to improve general operational performance and to reverse declining performance trends. Other plans are narrower in scope and usually address a single problem or type of problem. Their purpose is to correct the root cause(s) of a specific problem. Such corrective action plans may be included in the general plant improvement plan or may stand alone.

The appropriate scope of a corrective action plan will depend upon the nature and safety significance of the identified root-cause(s). The evaluation criteria presented in this document address the type of corrective action plan that focuses on a single type of problem, specifically, those related to communications.

\subsection{Scope and Applicability of the Evaluation Criteria}

Most activities in NPPs depend upon verbal and written communication and errors these communications can arise from a wide variety of root-causes in any operational area. The criteria defined in this document are composed of the following three elements:

(1) The licensee's root-cause analysis of communication errors is evaluated to ensure that its corrective actions reflect a thorough understanding of the problem(s) it addresses.

(2) The licensee's process for the development of corrective actions is evaluated to ensure that the corrective action(s) address the root causes of communication errors.

(3) The licensee's program for assessing the implementation and effectiveness of its corrective actions are evaluated to ensure that they are adequate. 
In addition to evaluating the corrective action plan and its supporting documentation, reviews include interviews with appropriate personnel and observation of the communications-related processes addressed by the plan.

The criteria for evaluating a root-cause analysis and the development of related corrective actions are not limited to communication errors. Although these criteria were written to address communication-related corrective actions, NRC personnel may also find them applicable and useful for evaluating root-cause analyses and for selecting and implementing corrective actions for other types of problems.

The evaluation criteria can also be applied to a variety of communication-related situations that occur in NPPs. For example, principles that underlie these evaluation criteria apply to communication in the following situations:

- between individuals

- within and among work groups

- in meetings

- in pre-job or pre-evolutions briefings

- during shift turnovers

The evaluation criteria can also be applied to written communications, such as policies, procedures, and maintenance work orders; however, these criteria do not necessarily apply to communications in all aspects of plant operations. Further, the practices that ensure effective communication within specific operational areas (e.g., maintenance work planning and procedure development) have been addressed in other industry and NRC documents targeted to those areas.

\subsection{Organization of this Document}

This document is presented in seven sections, as follows:

- Section 1 describes the purpose, scope, and applicability of the evaluation criteria and outlines the organization of this document.

- Section 2 provides background information concerning the communication process, common communication errors that occur in NPPs, commonly known root-causes of communication errors, development of corrective actions to address the root cause(s), the program for assessing the implementation and effectiveness of corrective actions, and the technical basis for the evaluation criteria.

- Section 3 presents criteria for evaluating (1) the root-cause analysis of communicationrelated events, (2) the development of corrective actions, and (3) the approach to implementing and monitoring the effectiveness of corrective actions

- Section 4 discusses appropriate interview protocols. 
- Section 5 discusses an observation protocol.

- Section 6 provides an Evaluation Criteria Worksheet

- $\quad$ Section 7 provides a Summary Rating Worksheet 


\section{BACKGROUND}

\subsection{Introduction}

This section provides background information concerning the following:

- the communication process

- common communication errors that occur in NPPs

- commonly known root causes of communication errors

- development of corrective actions to address the root cause(s)

- the program for assessing the implementation and effectiveness of corrective actions

- the technical basis for the evaluation criteria

This section may be useful to NRC personnel in several ways. First, it clarifies the terminology used in the remainder of this document. Second, it offers background information for NRC personnel who are not familiar with communication theory and practices. Finally, this discussion may aid the NRC personnel in defining areas of review when planning to investigate an event that involves communication errors.

\subsection{The Communication Process}

For the purposes of this document, the definition of communication divides the process into two sets of behaviors. Specifically, these behaviors are (1) creating and sending messages, and (2) receiving and interpreting them. As such, communication involves at least one sender and one receiver.

Successful communication requires several steps. To begin the process, the sender develops the intention to communicate particular information. The sender then composes a message (in written or verbal form) that presents the meaning as accurately as possible. The receiver attends to the message and interprets its meaning. If the communication is successful, the receiver constructs a meaning from the message that is similar to the meaning the sender had in mind when the message was created.

The similarity of the meanings attributed to the message by the sender and receiver can be verified through feedback, which is achieved through additional communication to ensure the receipt and proper understanding of the message. In some situations, it may be possible to verify the success of the communication by observing behavior. That is, did the receiver perform the actions either implied or explicitly stated in the message in the manner intended by the sender? In the NPP setting, feedback and supervisory oversight serve important error-checking functions in the communication process.

The sender and receiver(s) must both be active for communication to be effective, because they share responsibility for ensuring successful communication. However, the sender's actions in composing and transmitting the message are typically easier to observe than the receiver's actions in interpreting its meaning. Therefore, when analyzing the causes of events, failures in sending messages are more often identified than failures in receiving. For example, a written procedure may be blamed for causing an NPP worker to take an incorrect action, with the implication that the procedure writer(s) (the sender in this case) committed a communication error in constructing the message. That implication may not have been the case, however, and the fault may lie with the receiver. Perhaps, the NPP worker (i.e., the 
receiver) did not have an adequate level of knowledge to allow accurate interpretation of the procedure or the worker was confused by the wording of the procedure and failed to take responsibility for clearing up the confusion before taking action. If the receiver's role in the error is not accurately identified, corrective actions focused only on revising the procedure will not be completely effective.

Note that the basic process defined here applies to both verbal and written communications. An important difference between the two modes of communication is that, in written communication, the sender is typically less accessible to the receiver. Consequently, the kinds of interaction required to verify message receipt and understanding may be more difficult with written messages than with verbal communications.

\subsection{Errors in the Communication Process}

Verbal and written communication can fail in numerous ways. The lists of errors presented in this Section are not intended to be exhaustive. These lists simply provide examples of the types of sending and receiving errors that have been found to cause or contribute to events at NPPs, as reported in a sample of LERs and NRC inspection reports.

\subsubsection{Sending Errors}

Eight types of sending errors have been identified that can cause or contribute to events at NPPs:

(1) Message content is wrong. Communication fails because the information contained in the message is incorrect.

(2) Message content is inconsistent with other information. The information in the message is correct, but is partially or completely inconsistent with other information available to the receiver.

(3) Message content is inappropriate for the receiver. The sender fails to tailor the message in terms of the receiver's work context, the receiver's role in the task at hand, the receiver's level of technical knowledge, or the receiver's familiarity with the terminology used in composing the message.

(4) Message production is inadequate. After an accurate and complete message has been composed and tailored to the needs of the receiver, communication can fail if the message is not adequately produced. In verbal communication, poor production can lead to unclear transmission or a failure to make the "signal" stand out from the "background" noise. Sources of poor production may include communication equipment problems and ineffective use of language, such as ambiguous or vague references (e.g., use of the word "it," rather than the proper noun for a component). In written communication, production failures may mean poorly prepared documents (e.g., typographical errors, poor legibility, etc.).

Message is not sent. The sender fails to transmit a message needed by the receiver. 
Message is sent to the wrong place or person. Failures of this type can range from the sender not knowing where or to whom a message should be sent to such simple mistakes as dialing the wrong phone number.

(7) Message is sent at the wrong time. The timing of communications is highly important for coordinated work activities. Communication fails if the sender transmits a message either too early or too late for the receiver to use the information.

Failure to verify that the receiver understands the message. This error occurs when the sender fails to take positive actions to verify that the intended receiver has accepted and understood the message. In verbal communication, verification is obtained by requesting and correcting "repeatbacks" of the message. In written communication, verification cannot typically be obtained from each intended receiver, but can be tested with representative receivers. For example, conducting procedural walkthroughs with a subset of the potential users of the procedure is one way to test the users' ability to understand the intent of the procedure writer(s).

\subsubsection{Receiving Errors}

Four types of receiving errors have been identified that can cause or contribute to events at NPPs:

(1) Message is not sought. One of the receiver's responsibilities in the communication process at NPPs is to understand what information is needed to perform the task at hand, and where to obtain the information. A receiving error can occur if the receiver does not actively seek the information necessary to perform a task.

(2) Message is not found or is not used. Even when a correct message has been successfully transmitted to the appropriate person at the appropriate time, the communication can fail if the receiver (intentionally or unintentionally) does not find the necessary information or does not use it in task performance.

(3) Message is misunderstood. As with sending errors, there are many reasons that a receiver may misunderstand a message. Some of these reasons have more to do with sending (i.e., how the message is composed or transmitted) than with how the message is received. However, an adequate message that is successfully transmitted may still be misunderstood, particularly if the receiver lacks the technical knowledge to correctly interpret the message.

(4) Receiver does not verify with sender correct understanding of the message. This error occurs when the receiver fails to take actions to test his or her understanding of the message received. These actions may mean repeating or paraphrasing the message to the sender to check concurrence and to identify any gaps in the message or in the receiver's understanding of its meaning. 
Background

\section{$2.4 \quad$ Root Causes of Communication Errors}

Most work activities in NPPs are complex and require coordination within or among work groups. This coordination cannot be accomplished without effective verbal and written communication.

Communication is necessary to define both the work to be accomplished and how it is to be performed. Consequently, a wide array of causes can produce communication errors at NPPs.

A corrective action plan should show evidence that the root-cause analysis fulfilled the following criteria:

- $\quad$ Consider multiple possible causes for the error(s).

- Test the validity of the alternative possible causes to rule them out.

- Investigate the factors that created the root cause(s).

- Look for other instances in which similar communication errors occurred.

The appropriate level of effort and resources dedicated to a root-cause analysis depends on numerous factors. More serious events may require more thorough analyses. A noticeable increase in the frequency of communication errors may also trigger a thorough analysis.

\subsubsection{Commonly Known Root Causes}

Reviews of events at NPPs involving communication errors as either causal or contributory factors have identified the following types of root causes:

- Deficiencies in the document management program. Flaws in plant programs for developing and managing technical documentation are a source of written communication errors. Technical inaccuracies in vendor manuals, engineering analyses, or other documents may be translated into inaccuracies in procedures and work orders that are used to perform tasks. Failures to update drawings and procedures when plant hardware is modified also can result in written communication errors.

- Deficiencies in the work control program. Planning and scheduling maintenance activities is a complex task. Weaknesses in work control programs may result from both written and verbal communication errors associated with inadequate procedures and work orders, inadequate prejob briefings, and communication failures during task performance.

- Deficiencies in workload management. When planning for particular tasks, it is necessary to include an adequate number of staff members. Inadequate staffing can increase the workload for those performing the tasks, and thereby interfere with required communications. Increased workload during plant outages or off-normal events, for example, can tax the supervisory abilities of those responsible for coordinating the work, resulting in incomplete or too few communications. 
Deficiencies in technical knowledge. Effective communication requires some degree of shared understanding of the work to be performed. Inadequate job knowledge, resulting from deficient training or limited experience can lead to both sending and receiving errors.

- Deficiencies in organizational knowledge. In addition to a shared understanding of the work to be performed, effective communication depends upon an understanding of the information needs of those involved in performing a task. Communication across organizational boundaries (e.g., among individuals in different departments, in different job roles, or on different shifts) can cause problems because senders and receivers may not understand one another's terminology or the contexts and constraints of the other's job.

- Deficiencies related to communication-related devices. This category of root causes pertains to communications that must occur across physical distances through communication-related devices. Errors of this type can arise, for example, when there is too much background noise for a receiver to hear a public address (PA) announcement or to be able to hear what is being said on the radio or over the phone. An insufficient number of radio frequencies to support communication needs can also cause or contribute to communication errors. Inadequate training in the use of communication-related devices may also prevent or impair communication.

Deficiencies in managerial oversight and supervision. Some communication failures occur as a result of human errors in task performance. Often, however, these errors can be caught and corrected through independent observation and supervisory oversight of task performance. Deficiencies in plant programs for determining which tasks require independent oversight or for ensuring that appropriately trained staff are available to perform this supervisory function can cause communication-related error-checking failures.

- Deficiencies in communication behavior. Lack of communication skills or failure to apply standard verbal and written communication practices are frequently cited as root causes for communication errors in NPPs.

The above list represents the most common categories of root causes cited in LERs and inspection reports. Nevertheless, the causes of specific communication errors are often more complex than these categories would suggest. These and other factors often combine to result in the reportable events or trends and patterns that lead to a corrective action plan.

Of the many factors that can contribute to the occurrence of communication errors, some result from inadequate communication behavior by those involved in sending and receiving the message. Other failures are external to the communication process and result from factors beyond the communicators' direct control. In the former case, effective corrective actions focus on improving communication behavior (e.g., training to encourage repeat-backs before taking actions). In the latter case, the communication error occurs as a symptom of other causes (e.g., communication equipment failures). The effectiveness of corrective actions therefore depend, in part, upon understanding the sources for the errors that have occurred and the design and implementation of corrective actions to address those specific sources of error. 
Background

To illustrate this point, consider a sending error where the message is not sent to a receiver who needs the information to correctly perform some task. This error may result from several different root causes. For example, all of the individuals who must be informed that a component or system is going to be taken out of service for maintenance may not be identified during planning for the task. In NPPs, this type of error often results from planning and scheduling deficiencies. Work orders may be written that do not include instructions to inform some of the affected parties. As a result, workers who are performing a task that is affected by a tag-out, for example, may not be informed when the work begins. A second significant root cause for this error is workload. A high workload (or some peripheral distraction) can prevent the sender from taking time to send a message. Finally, a failure of communications equipment might prevent a message from being sent (e.g., an auxiliary operator is under direction from the control room, but is in an area of the plant where the background noise is too high to hear PA announcements and his or her radio cannot be used). As computer-based communications (e.g., e-mail) assume a larger role in the coordination of work at NPPs, errors associated with computer-based communication may increase.

\subsubsection{Example of Root-Cause Analysis}

A root-cause analysis should be sufficiently in-depth to present evidence of an understanding of why the identified errors occurred. As an example of an in-depth analysis, consider the following series of hypothetical events:

An auxiliary operator $(A O)$ was assigned the task of taking a leak-rate measurement. One of the licensed operators in the control room paged him over the PA system to tell him to take the measurement, but the AO picked up the phone in a noisy area and wasn't exactly sure where he was to go. Consequently, he measured the leakage from a different system and called his findings back to the control room, causing the operators to conclude that the leak rate was holding steady.

In actuality, the rate of the leakage in the piping that the $A O$ should have inspected had substantially increased and exceeded the technical specification limits since the last measurement was taken. In addition, the water leaking from the piping intended to be measured was contaminated and had overflowed its containment. By the time the situation was discovered, a large pool of contaminated water had formed on the floor under the pipe.

A thorough root-cause analysis of this event might explore all of the following possible alternative explanations:

- A sending error occurred in which the control room operator failed to tell the AO where the leak was located or gave incorrect location information.

- A receiving error occurred in which the AO misinterpreted the location information.

- The AO could not hear the complete message because of background noise.

- The operator and the AO failed to confirm that the correct information had been sent and accurately received. 
Depending upon which of these explanations best described the event, the licensee would then investigate the causal factors that led to the particular circumstances in which the event occurred. For example, if the operator failed to tell the $A O$ where the leak was located, the licensee would explore such questions as "Did the operator know the exact location of the leak?" and "If not, why not?". A deficiency in information transmittal during shift turnover in the control room may be identified as the root cause for the operator not being sure where the leak was located. In that event, the licensee would examine shift turnover communication practices, training for shift turnover, and the shift turnover procedure to assess whether any of these specifically required the operator to communicate the location information. In addition, the licensee might screen previous LERs or other records of past events to determine whether incomplete communications during shift turnover had played a causal role in other events.

\subsection{Development of Corrective Actions}

Once the licensee identifies and validates the root causes of communication errors, the second step in developing corrective actions is to define the improvements needed to ensure that the communication errors will not recur. This is not a simple task. Corrective actions for human performance problems, such as communication errors, often require changes in behavior and the individuals who must change may resist. In addition, the most appropriate approach to creating and reinforcing behavioral changes may not always be obvious from the available alternatives.

Industries where safe operations are a concern most often adopt an approach to managing human performance that involves setting up multiple "barriers" to human error. These barriers typically include the following strategies:

- procedures

- training

- human-system interface design

- fault-tolerant system design

- management systems for defining and organizing work flow

- immediate supervision

- quality control programs

Corrective actions for communication problems may entail adding new barriers or strengthening existing barriers against error. New barriers might include writing a procedure for a task that was not previously proceduralized. Strengthening existing barriers might include redesigning a training module or revising a procedural step. Many corrective action plans include a combination of adding new barriers and strengthening those that already exist.

\subsection{Corrective Action Implementation and Effectiveness}

Implementation of corrective actions and the methods selected for ongoing evaluation of its effectiveness should be included in the overall plan. Corrective actions sometimes fail in the implementation phase, for example, because the steps for achieving corrective action objectives were not defined in adequate 
Background

detail, because responsibility for accomplishing the objectives was not assigned to specific individuals, or because measures for assessing the success of the corrective actions were not defined. Further, other management initiatives and events may arise and take precedence over implementing corrective actions. Without a method for monitoring the ongoing effectiveness of corrective actions, communication errors may recur.

\subsection{Technical Basis for Evaluation Criteria}

Defining the technical basis for evaluating communications-related corrective action plans involved developing a model of communications in NPPs and systematically reviewing LERs and inspection reports that document verbal and written communication errors in NPPs. The resulting communications model and the findings of the systematic review were used in combination with an abbreviated literature review and input from a panel of subject matter experts to develop evaluation criteria for NRC personnel to use in evaluating licensees' communications-related corrective action plans.

The evaluation criteria were developed using the following source documents:

Barnes, V., R. Mumaw, J. DeBor, and C. Moore, "Technical Assistance for Development of Review Guidelines for Evaluating Corrective Action Plans for NPP Communications Related to Events:

Summary Task Letter Report for Subtasks 8.1-8.3." Appendix A, "Proposed Scheme for Coding Verbal and Written Communications Errors: A Model of Communications in Nuclear Power Plants." Science and Engineering Associates, Inc., June 23, 1995. This document is publicly available via NUDOCS Accession No. 9611180243.

Barnes, V., R. Mumaw, and J. DeBor, "Summary of the Subject Matter Expert Panel Meeting: Task 8.4 Letter Report," Science and Engineering Associates, Inc., July 19, 1995. This document is publicly available via NUDOCS Accession No. 9611180176. 


\section{EVALUATION CRITERIA ELEMENTS}

Evaluation criteria are organized according to three elements:

(1) The licensee's root-cause analysis of communication errors is evaluated to ensure that its corrective actions reflect a thorough understanding of the problem(s) it addresses.

(2) The licensee's process for the development of corrective actions is evaluated to ensure that the corrective action(s) effectively address the root cause(s) of communication errors.

(3) The licensee's program for assessing the implementation and effectiveness of its corrective actions are evaluated to ensure that the plan is adequate.

For each element, the following subsections include (1) applicable evaluation criteria, (2) general and specific guidance, and (3) a rating scale for each criterion. In each case, the rating scale uses $\mathrm{A}, \mathrm{B}$, and C designations, which are specifically defined for each criterion.

Note: The Interview Protocol (Section 4) and the Observation Protocol (Section 5) also use the evaluation criteria defined in this section. Hence, the Evaluation Criteria Worksheet (Section 6) includes a rating scale for these criteria.

\subsection{Element 1 - Root-Cause Analysis}

Conduct an evaluation of Element 1 using the general and specific guidance in addition to the following evaluation criteria:

(1.1) The root-cause analysis has considered an array of possible root causes.

(1.2) The root-cause analysis has been derived from an events and causal-factors analysis.

(1.3) The root-cause analysis has used appropriate methods to investigate the possible causes.

(1.4) The basis for rejecting possible root causes has been documented.

(1.5) The root-cause analysis has identified and analyzed related events.

(1.6) A rationale for terminating the root-cause analysis has been documented.

(1.7) The basis for the conclusion(s) has been documented.

Rate each criterion A, B, or C, and record the ratings on the Evaluation Criteria Worksheet (Section 6). 
Evaluation Criteria Elements

(1.1) The root-cause analysis has considered an array of possible root causes

\section{General Guidance}

A root-cause analysis should have the following characteristics:

- The analysis should investigate more than one possible explanation for a communication error.

- The root-cause analysis should focus on understanding the primary cause(s) of the communication-related event.

\section{Specific Guidance}

Review the root-cause analysis and other event analysis reports. Interview the individual(s) responsible for conducting the root-cause analysis and the person(s) involved in the communication event.

\section{Criterion Rating}

How many possible root causes were investigated?
A. An array
B. Several, but other possible causes were omitted
C. Only one for each communication error

Record your rating of this criterion on the Evaluation Criteria Worksheet. 
(1.2) The root-cause analysis has been derived from an events and causal-factors analysis

\section{General Guidance}

A thorough root-cause analysis should be derived from the following bases:

- a chart or analysis depicting the relevant events and causal factors

- an analysis of the sequence of events that led to the communication error, as well as the causal factors that contributed to those events

An events and causal factors analysis is a graphic presentation of the sequence of events that led to an accident or incident and the potential reasons (causal factors) for those events. The analysis helps the investigator (1) understand the event progression, (2) identify holes and inconsistencies in the information, and (3) explain the event to others.

\section{Specific Guidance}

Determine if the licensee conducted an events and causal factors analysis that led to a root-cause analysis. Interview the individual(s) responsible for conducting the root-cause analysis.

\section{Criterion Rating}

Was the root-cause analysis derived from an events and causal-factors analysis?
A. Yes
B. No; however, another analytical tool was used
C. No

Record your rating of this criterion on the Evaluation Criteria Worksheet. 
(1.3) The root-cause analysis has used appropriate methods to investigate the possible causes

\section{General Guidance}

The licensee should have determined the event causes using appropriate methods, such as the following examples:

- interviews (face-to-face discussions)

- barrier analysis (to identify the factors that, if avoided, would have prevented the event from occurring)

- change analysis (a systematic approach for identifying changes in the process that may have contributed to an event)

- critical incident techniques (to identify critical actions that, if performed correctly, would have prevented the event from occurring or would have significantly reduced the event's consequences)

- fault tree analysis (a qualitative or quantitative analysis that emphasizes the relationships among events and the probability of event occurrence)

- the Human Performance Investigation Process (HPIP) (the NRC's systematic investigation process for understanding human performance issues that cause events)

- Management Oversight and Risk Tree (MORT) (a systematic process using analytic techniques to determine the cause of problems)

Interviewing those involved in communication error(s) is the most common method used in root-cause analyses. However, information from interviews can be biased or limited in other ways. For example, people's memories of events are often faulty, and different individuals who have experienced the same event frequently remember it differently and give conflicting accounts. As another example, people have difficulty understanding and describing the factors that influence their behavior and decisions, in general, and particularly in retrospect. Although interviews are a key source of information for root-cause analyses, the licensee should augment interview findings through the use of systematic event investigation tools such as those previously listed.

Detailed discussions of investigative techniques can be found in "Development of the NRC's Human Performance Investigation Process (HPIP): Volume 2, Investigator's Manual," NUREG/CR-5455, U.S. Nuclear Regulatory Commission/System Improvements, Inc., October 1993.

\section{Specific Guidance}

Review the licensee's root-cause analysis reports. Interview the individual(s) responsible for conducting the root-cause analysis. 
Evaluation Criteria Elements

\section{Criterion Rating}

How many methods were used in addition to interviews?
A. Several
B. One
C. None

Record your rating of this criterion on the Evaluation Criteria Worksheet. 
Evaluation Criteria Elements

(1.4) The basis for rejecting possible root causes has been documented

\section{General Guidance}

Reviewing the licensee's rationale for ruling out alternative possible root cause(s) assists in ensuring the validity of the specific root cause(s) identified. The evidence used to rule out alternatives will also be useful for future reference if communication errors continue to occur after the licensee implements the corrective actions.

\section{Specific Guidance}

Review the root-cause analysis reports. Interview the individual(s) responsible for conducting the rootcause analysis.

\section{Criterion Rating}

Was a rationale provided for ruling out possible root causes?
A. Yes, for all root causes ruled out
B. Yes, for some root causes ruled out
C. No

Record your rating of this criterion on the Evaluation Criteria Worksheet. 


\section{(1.5) The root-cause analysis has identified and analyzed related events}

\section{General Guidance}

Related events should be reviewed to determine the possible extent of the problem. Identifying other instances in which communication errors have occurred and determining the causes for those errors may reveal that the root cause for the error under investigation has had other effects. This information further validates the root cause identified.

For problems involving human performance, "related" events may be defined in terms of human factors, as follows:

- events involving other similar communication errors, whether or not the same hardware was involved

- $\quad$ events involving personnel in the same job roles who perform the same tasks

- $\quad$ events involving personnel who have experienced the same type of training

- $\quad$ events involving personnel who work for the same supervisor

- $\quad$ events that occurred while performing the same procedure

\section{Specific Guidance}

Review the root-cause analysis reports. Interview the individual(s) responsible for conducting the rootcause analysis.

\section{Criterion Rating}

Did the root-cause analysis identify and analyze related events?
A. Yes, other instances in which events have occurred have been identified and analyzed.
B. Yes, other related events have been identified but they have not been analyzed.
C. No, the licensee has not attempted to identify related events.

Record your rating of this criterion on the Evaluation Criteria Worksheet. 


\section{(1.6) A rationale for terminating the root-cause analysis has been documented}

\section{General Guidance}

Causal analyses theoretically could progress without end (e.g., an error in a single procedure triggers an investigation of all facility procedures, all policies on use of procedures, training of procedure writers, procedure program definition documents, general policy and technical basis documents used in developing the procedures, and the administrative procedures that govern the procedure program, etc.). Alternatively, the analysis could stop as soon as one cause is identified (e.g., there may be no consideration of how an error in a given procedure occurred).

If the analysis is terminated prematurely, the corrective actions will address only some of the actual problem(s) and will not prevent future events. However, because no widely accepted standard exists to define an appropriately thorough analysis, it will be necessary to review of the basis for terminating the analysis, and its adequacy must be judged on a case-by-case basis.

\section{Specific Guidance}

Review the root-cause analysis reports. Interview the individual(s) responsible for conducting the rootcause analysis.

\section{Criterion Rating}

Has the rationale for terminating the analysis been documented?
A. Yes
B. Yes; however, the rationale suggests that the analysis was terminated prematurely
C. No

Record your rating of this criterion on the Evaluation Criteria Worksheet. 


\section{(1.7) The basis for the conclusions has been documented}

\section{General Guidance}

Documentation of the root-cause analysis is important for communicating the basis of a corrective action to ensure that the conclusions are substantiated by facts that can be verified. The documentation will also be useful in future evaluations if a corrective action proves to be ineffective.

\section{Specific Guidance}

Review the root-cause analysis reports. Interview the individual(s) responsible for conducting the rootcause analysis. Interview the person(s) involved in the communications event addressed in corrective actions.

\section{Criterion Rating}

Has the basis for conclusion(s) been documented?
A. Yes, all
B. Yes, some
C. No

Record your rating of this criterion on the Evaluation Criteria Worksheet. 


\subsection{Element 2 - Development of Corrective Actions}

Conduct an evaluation of Element 2 using the general and specific guidance in addition to the following evaluation criteria:

(2.1) The linkages have been specified between the root cause(s) identified and the corrective actions proposed.

(2.2) The licensee has identified the desired condition(s) that the corrective actions are intended to achieve.

(2.3) The type of work situations have been specified in which formal communication practices are required.

(2.4) The corrective actions define methods for senders to verify the accuracy of the information to be communicated.

(2.5) The corrective actions have been provided for ensuring that the level of detail in messages is sufficient for and tailored to the receiver's information needs.

(2.6) The corrective actions define vocabulary requirements.

(2.7) The corrective actions define methods for identifying equipment and systems.

(2.8) The corrective actions define methods for identifying personnel involved in verbal communications.

(2.9) The corrective actions define methods for ensuring that senders and receivers understand the communication requirements of a task before task performance.

(2.10) The corrective actions define methods for receivers to verify message receipt, to verify message understanding, and to question conflicting or incomplete messages.

(2.11) The corrective actions ensure that receivers will seek messages that were expected but were not received.

Rate each criterion A, B, or C, and record the ratings on the Evaluation Criteria Worksheet (Section 6). It is anticipated that Criterion 2.1 above will always be relevant to a review of a licensee's root cause(s) and associated corrective actions. However, NRC personnel may find that all the remaining criteria will not necessarily always be applicable in a particular review. 
(2.1) The linkages have been specified between the root cause(s) identified and the corrective actions proposed

\section{General Guidance}

The corrective actions should have linkages to the root-cause analysis; however, the following additional guidance should be considered:

- Each identified communication error may not correspond to a specific corrective action because communication errors may be symptoms of other causal factors that are not directly related to communication behavior.

- Corrective actions for communication errors may address other causal factors.

- It is necessary to verify that the relationship is established between identified root causes and proposed corrective actions for communication errors.

\section{Specific Guidance}

Review the documentation for corrective actions. Interview the individual(s) responsible for developing the corrective actions. Using the Communications Observation Protocol (Section 5), observe personnel to determine if the corrective actions have been effective.

\section{Criterion Rating}

Which of the following statements best describes the linkage between root causes identified as being directly related to communication behavior and proposed corrective actions?
A. Linkage exists for all
B. Linkage exists for several
C. Linkage exists for one or none

Record your rating of this criterion on the Evaluation Criteria Worksheet. 
Evaluation Criteria Elements

(2.2) The licensee has identified the desired condition(s) that the corrective actions are intended to achieve

\section{General Guidance}

A desired condition is a statement of the goal that the corrective actions should achieve. A clear description of the desired condition serves at least three purposes:

- Assist NPP personnel in understanding why existing conditions are unacceptable.

- Describe the basis underlying the need for change.

- $\quad$ Assist NPP workers in accepting more stringent performance standards.

\section{Specific Guidance}

Review the documentation for corrective actions. Interview the individual responsible for developing the corrective actions. Using the Communications Observation Protocol (Section 5), observe personnel to determine if the corrective actions have been effective.

\section{Criterion Rating}

Has the licensee identified the desired conditions(s) that the corrective actions are intended to achieve?
A. All
B. Several
C. One

Record your rating of this criterion on the Evaluation Criteria Worksheet. 


\section{(2.3) The types of work situations have been specified in which uniform communication} practices are required

\section{General Guidance}

Some tasks at NPPs depend heavily on the ability of workers to coordinate their tasks and, therefore, require uniform communication practices to reduce the likelihood of communication errors. Uniform communications practices include written procedures and work orders, as well as some verbal exchanges. Reviews of events at NPPs suggest that uniform communication practices are required for the following communications (as a minimum):

- between members of different work groups

- during shift turnover

- $\quad$ remote (not face-to-face)

- during pre-job and pre-evolution briefings

- when planning for and performing work activities that may entail risk

- when planning for and performing time-critical tasks

- $\quad$ during periods of high workload

- when performing infrequent and unfamiliar tasks

\section{Specific Guidance}

Review the documentation for corrective actions. Interview the individual(s) responsible for developing the corrective actions. Using the Communications Observation Protocol (Section 5), observe personnel to determine if the corrective actions have been effective.

\section{Criterion Rating}

Has the licensee identified the types of work situations for which uniform communication practices are required?
A. Several
B. One
C. None

Record your rating of this criterion on the Evaluation Criteria Worksheet. 
Evaluation Criteria Elements

(2.4) The corrective actions defined methods for senders to verify the accuracy of the information to be communicated

\section{General Guidance}

Before composing and sending a message, senders are responsible for verifying, to the extent possible, the accuracy of the information they will be transmitting. This responsibility might require the sender, for example, to question supervisors about a procedural step or a command that appears to conflict with other information available to the sender, before passing on potentially inaccurate information.

\section{Specific Guidance}

Review the documentation for corrective actions. Interview the individual(s) responsible for developing the corrective actions. Using the Communications Observation Protocol (Section 5), observe personnel to determine if the corrective actions have been effective.

\section{Criterion Rating}

Do the corrective actions define methods for verifying the accuracy of the information to be communicated?
A. Several
B. One
C. None

Record your rating of this criterion on the Evaluation Criteria Worksheet. 
(2.5) The corrective actions have been provided for ensuring that the level of detail in messages is sufficient for and tailored to the receiver's information needs

\section{General Guidance}

It is essential for the sender to ensure that the information transmitted in a message provides the appropriate level of detail and highlights the important aspects of the message. In so doing, the sender tailors the message to the receiver's information needs. The sender may also need to understand the receiver's work environment and usual roles and responsibilities.

\section{Specific Guidance}

Review documentation for corrective actions. Interview the individual(s) responsible for developing the corrective actions. Using the Communications Observation Protocol (Section 5), observe personnel to determine if the corrective actions have been effective.

\section{Criterion Rating}

Would the corrective actions ensure that the level of detail in messages is sufficient for and tailored to the receiver's information needs?
A. Yes
B. Somewhat
C. No

Record your rating of this criterion on the Evaluation Criteria Worksheet. 
(2.6) The corrective actions define vocabulary requirements

\section{General Guidance}

For written communications, such as procedures, many licensees have developed lists of acceptable common nouns and action verbs that are to be used consistently in written communications. These same terms should also be used in verbal communications. In verbal communications may also entail the following additional vocabulary requirements:

- Use simple words and phrases for concise messages.

- Avoid words that sound alike (e.g., use "lower" rather than "decrease," because "decrease" can be difficult to discriminate from "increase").

- Use the phonetic alphabet for acronyms and abbreviations ("alpha" for A, "bravo" for B, etc.).

- Use words that precisely describe what the sender expects the receiver to do or observe.

\section{Specific Guidance}

Review the documentation for corrective actions. Interview the individual(s) responsible for developing the corrective actions. Using the Communications Observation Protocol (Section 5), observe personnel to determine if the corrective actions have been effective.

\section{Criterion Rating}

Do the corrective actions define vocabulary requirements?
A. Yes
B. Somewhat
C. No

Record your rating of this criterion on the Evaluation Criteria Worksheet. 


\section{(2.7) The corrective actions define methods for identifying equipment and systems}

\section{General Guidance}

Identification methods should include the use of complete names, alphanumeric equipment or system identifiers, unit designator, and locations of the equipment or system(s). These identification methods are applicable to written procedures and work orders, as well as verbal communications.

\section{Specific Guidance}

Review the documentation for corrective actions. Interview the individual(s) responsible for developing the corrective actions. Using the Communications Observation Protocol (Section 5), observe personnel to determine if the corrective actions have been effective.

\section{Criterion Rating}

Do the corrective actions define methods for identifying equipment and systems?
A. Yes
B. Somewhat
C. No

Record your rating of this criterion on the Evaluation Criteria Worksheet. 
(2.8) The corrective actions define methods for identifying personnel involved in verbal communications

\section{General Guidance}

In verbal communications that do not occur face-to-face, senders and receivers should identify themselves at the start of the communication by personal name, job role, and location in the plant. In circumstances where the communicators are physically co-located, but there may be more than one potential receiver (such as within-crew communications in the control room), the sender should address statements to the intended receiver prefaced with the receiver's name. The receiver should preface his or her verification of message receipt with the sender's name.

\section{Specific Guidance}

Review the documentation for corrective actions. Interview the individual(s) responsible for developing the corrective actions. Using the Communications Observation Protocol (Section 5), observe personnel to determine if the corrective actions have been effective.

\section{Criterion Rating}

Do the corrective actions define methods for identifying personnel involved in verbal communications?
A. Yes
B. Somewhat
C. No

Record your rating of this criterion on the Evaluation Criteria Worksheet. 
(2.9) The corrective actions define methods for ensuring that senders and receivers understand the communication requirements of a task before task performance

\section{General Guidance}

These methods may include adding instructions to the procedures and work orders that will govern a task. Communication requirements should also be reviewed during pre-job or pre-evolution briefings. Communication roles and responsibilities should be assigned, and the required timing for the communications should be addressed.

\section{Specific Guidance}

Review the documentation for corrective actions. Interview the individual(s) responsible for developing the corrective actions. Using the Communications Observation Protocol (Section 5), observe personnel to determine if the corrective actions have been effective.

\section{Criterion Rating}

Do the corrective actions define methods for ensuring that senders and receivers understand the communication requirements of a task before task performance?
A. Yes
B. Somewhat
C. No

Record your rating of this criterion on the Evaluation Criteria Worksheet. 
Evaluation Criteria Elements

(2.10) The corrective actions define methods for receivers to verify message receipt, to verify message understanding, and to question conflicting or incomplete messages

\section{General Guidance}

As active participants in the communication process, receivers are responsible for notifying the sender that the message has been received and for ensuring that it was accurately understood. Receivers must also maintain a questioning attitude during communications and take responsibility for clarifying with the sender any inconsistent, incomplete, or unclear messages.

\section{Specific Guidance}

Review the documentation for corrective actions. Interview the individual(s) responsible for developing the corrective actions. Using the Communications Observation Protocol (Section 5), observe personnel to determine if the corrective actions have been effective.

\section{Criterion Rating}

Do the corrective actions define methods for receivers to verify message receipt, to verify message understanding, and to question conflicting or incomplete messages?
A. Yes
B. Somewhat
C. No

Record your rating of this criterion on the Evaluation Criteria Worksheet. 
(2.11) The corrective actions ensure that receivers will seek messages that were expected but were not received

\section{General Guidance}

The timing of communications can be critical to accurate task performance. If a receiver expects information that is not provided when expected, it is the receiver's responsibility to seek the information.

\section{Specific Guidance}

Review the documentation for corrective actions. Interview the individual(s) responsible for developing the corrective actions. Using the Communications Observation Protocol (Section 5), observe personnel to determine if the corrective actions have been effective.

\section{Criterion Rating}

Do the corrective actions ensure that receivers will seek messages that were expected but were not received?
A. Yes
B. Somewhat
C. No

Record your rating of this criterion on the Evaluation Criteria Worksheet. 
Evaluation Criteria Elements

\subsection{Element 3 - Corrective Action Implementation and Effectiveness}

Conduct an evaluation of Element 3 using the general and specific guidance in addition to the following evaluation criteria:

(3.1) Measurable objectives to be achieved from implementing corrective actions have been defined.

(3.2) Evaluation criteria have been defined.

(3.3) Monitoring of corrective action effectiveness has been addressed.

(3.4) Corrective actions have been reviewed before implementation to ensure that they do not cause unintended negative consequences.

Rate each criterion A, B, or C, and record the ratings on the Evaluation Criteria Worksheet. 
(3.1) Measurable objectives to be achieved from implementing the corrective actions have been defined

\section{General Guidance}

Measurable objectives provide the means for determining whether corrective actions have been effective and the desired condition achieved. Objectives represent specific conditions or changes in performance that can be quantified and measured.

Specific Guidance

Review the documentation to assess the implementation and effectiveness of corrective actions. Interview the individual(s) responsible for implementing the corrective actions.

\section{Criterion Rating}

Which of the following statements best describes the approach used to assess the implementation and effectiveness of the corrective actions?
A. Measurable objectives to be achieved for all phases of corrective actions have been defined.
B. Objectives have been defined; however, they are not measurable.
C. Objectives have not been defined.

Record your rating of this criterion on the Evaluation Criteria Worksheet. 


\section{(3.2) Evaluation criteria have been defined}

\section{General Guidance}

Evaluation criteria are the indicators to show that objectives and desired conditions of the corrective actions have been achieved. These criteria should also include a process and specific performance indicators for evaluating how the steps have been implemented. For example, the indicators may include documentation that implementation steps have been completed and that the steps have had the desired outcomes. Such performance indicators are often used to provide evidence that corrective actions were effective.

The following is one example of an implementation step and the related indicators and evaluation criteria for verbal communications training:

Step:

The training department will develop materials and train maintenance personnel in standard verbal communication practices.

Indicators:

- $\quad$ Produce the training materials (learning objectives, course outline, curriculum materials, and tests).

- Compile a list of personnel attending the training.

- Compile a listing of test scores.

Evaluation

Criteria:

- Do the training materials address the issues involved and the behavioral changes required?

- $\quad$ Are the materials geared for the target audience?

- Did the entire target audience attend a training session?

- Was the training test cursory or thorough and objective?

- Were test scores satisfactory?

- On the basis of field observations over time, does actual practice now comply with standard verbal communication requirements?

\section{Specific Guidance}

Review the documentation (including trend-related data) to assess the implementation and effectiveness of corrective actions. Interview the individual(s) responsible for implementing the corrective actions. Using the Communications Observation Protocol (Section 5), observe personnel to determine if the corrective actions have been effective.

\section{Criterion Rating}

Have evaluation criteria been defined?

A. Yes 
B. Yes, but they're not being used

C. No

Record your rating of this criterion on the Evaluation Criteria Worksheet. 
Evaluation Criteria Elements

(3.3) Monitoring of corrective action effectiveness has been addressed

\section{General Guidance}

Implementation of a corrective action or general plant improvement plan will not usually provide a permanent solution to communication problems. In general, the desired conditions that were achieved from the plan may degrade as top managers change, as new programs are implemented, as the work force changes, and so on. Consequently, a plan for monitoring continued acceptable performance including trending is desirable.

Implementation should include a series of steps that need be completed to achieve the objectives of the corrective actions. Each step in the implementation should be an activity that a specified individual is accountable for achieving on a certain schedule.

\section{Specific Guidance}

Review the documentation (including trend-related data) to assess the implementation and effectiveness of corrective actions. Interview the individual(s) responsible for implementing the corrective actions.

\section{Criterion Rating}

Has the licensee specified a method for monitoring corrective actions?
A. Yes
B. Somewhat
C. No

Record your rating of this criterion on the Evaluation Criteria Worksheet. 


\section{Corrective actions have been reviewed before implementation to ensure that they do not cause unintended negative consequences}

\section{General Guidance}

Hidden costs and risks are often associated with making changes. When large-scale changes are implemented in policies, programs, processes, procedures, or work practices, human errors become more likely during an adjustment period. In addition to the possible effects of resistance to change, some delays and difficulties in performing work may be introduced as workers are faced with unfamiliar tasks, familiar tasks to be performed in new ways, or requirements to interact with new and unfamiliar people in new jobs or in different departments.

Corrective action plans should consider risks and likely disruptions caused by implementing the changes and should provide an approach for minimizing these risks and disruptions. For example, interim processes and procedures may have to be developed to ease the transition from old work practices to new, or the corrective action plan may require that all employees affected by a change complete training before the change is implemented.

NRC personnel should note that errors and disruptions that occur during and immediately following plan implementation may not reflect inadequacies in the corrective actions. Rather, these problems may be caused by the change process itself and inadequate planning for it.

\section{Specific Guidance}

Review the licensee's documentation to assess the potential impacts of implementing the corrective actions. Interview the individual(s) responsible for implementing the corrective actions.

\section{Criterion Rating}

Has the licensee considered potential negative impacts of implementing the corrective actions?
A. Yes
B. Yes, but no strategy has been specified to address the potential negative impact
C. No

Record your rating of this criterion on the Evaluation Criteria Worksheet. 


\section{INTERVIEW PROTOCOLS}

This section defines protocols to be used in documenting the results of interviews which will usually need to be conducted with licensee personnel. The individuals interviewed should be those who were responsible for and actually completed the root-cause analysis, developed the corrective actions, and formulated the implementation plan for resolving communications-related issues.

The interview questions focus on the three elements (i.e., root-cause analysis, development of corrective actions, and corrective action implementation and effectiveness). Each of these elements relates to criteria used to evaluate the communications corrective actions. The numbers in parentheses following the items correspond to the criteria in the Evaluation Criteria Worksheet. The ratings should be transferred to that worksheet.

The purpose of an interview is not to obtain an answer to every question in the protocol, but rather to obtain sufficient information to achieve the goals of the evaluation. The protocols provide a logical framework for obtaining a variety of information but can--and should--be modified to make the protocols more useful for each specific situation. The interviewer should review the questions ahead of time, and should add questions to address specific identified problems.

After completing the interviews, review the results for each of the following communications-related elements:

- root-cause analysis

- development of corrective actions

- $\quad$ corrective action implementation and effectiveness

If the results suggest that a problem may exist in an element, further evaluation is warranted. Information obtained using questions added to the protocols should also be reviewed when determining if evaluation of a particular element is needed. 


\begin{tabular}{|c|c|c|c|}
\hline \multicolumn{4}{|l|}{ 4.1 Root-Cause Analysis Interview Protocol } \\
\hline $\begin{array}{l}\text { Date: } \\
\text { Interviewee: } \\
\text { Interviewer: }\end{array}$ & \multicolumn{3}{|c|}{$\begin{array}{l}\text { Circle rating on } \\
\qquad \begin{array}{l}\mathrm{A}=\text { excellent } \\
\mathrm{B}=\text { satisfactory } \\
\mathrm{C}=\text { poor }\end{array} \\
\text { Record rating on Evaluation } \\
\text { Criteria Worksheet }\end{array}$} \\
\hline $\begin{array}{l}\text { (1) Describe how the root-cause analysis considered an array of } \\
\text { possible root causes for the error or trend of error. (1.1) }\end{array}$ & A & B & $\mathrm{C}$ \\
\hline $\begin{array}{l}\text { (2) Describe how the root-cause analysis was derived from an } \\
\text { events and causal-factors analysis. (1.2) }\end{array}$ & A & $\mathrm{B}$ & $\mathrm{C}$ \\
\hline $\begin{array}{l}\text { (3) Describe the methods used to investigate the possible } \\
\text { causes. (1.3) }\end{array}$ & A & B & $\mathrm{C}$ \\
\hline $\begin{array}{l}\text { (4) Describe the documentation concerning the basis for } \\
\text { rejecting possible root causes. (1.4) }\end{array}$ & A & B & $\mathrm{C}$ \\
\hline $\begin{array}{l}\text { (5) Describe how related events are identified and analyzed? } \\
\text { (1.5) }\end{array}$ & A & $\mathrm{B}$ & $\mathrm{C}$ \\
\hline (6) Describe the rationale used to terminate the analysis. (1.6) & A & $\mathrm{B}$ & $\mathrm{C}$ \\
\hline $\begin{array}{l}\text { (7) Describe the documentation concerning the basis for the } \\
\text { conclusion(s). (1.7) }\end{array}$ & A & $\mathrm{B}$ & $\mathrm{C}$ \\
\hline
\end{tabular}




\begin{tabular}{|c|c|c|c|}
\hline $\begin{array}{l}\text { Date: } \\
\text { Interviewee: } \\
\text { Interviewer: }\end{array}$ & \multicolumn{3}{|c|}{$\begin{array}{l}\text { Circle rating on } \\
\qquad \begin{array}{l}A=\text { excellent } \\
B=\text { satisfactory } \\
C=\text { poor }\end{array} \\
\text { Record rating on Evaluation } \\
\text { Criteria Worksheet }\end{array}$} \\
\hline $\begin{array}{l}\text { (1) Describe the linkages that were specified between the root } \\
\text { causes and the corrective actions. (2.1) }\end{array}$ & A & B & $\mathrm{C}$ \\
\hline $\begin{array}{l}\text { (2) Describe the desired conditions that the corrective actions } \\
\text { are intended to achieve. (2.2) }\end{array}$ & A & B & $\mathrm{C}$ \\
\hline $\begin{array}{l}\text { (3) Define the types of work situations in which uniform } \\
\text { communication practices are required. (2.3) }\end{array}$ & A & B & $\mathrm{C}$ \\
\hline
\end{tabular}




\begin{tabular}{|c|c|c|c|c|}
\hline \multicolumn{5}{|c|}{ 4.2 Development of Corrective Action Interview Protocol } \\
\hline \multicolumn{2}{|c|}{$\begin{array}{l}\text { Date: } \\
\text { Interviewee: } \\
\text { Interviewer: }\end{array}$} & \multicolumn{3}{|c|}{$\begin{array}{l}\text { Circle rating on } \\
\qquad \begin{array}{l}A=\text { excellent } \\
B=\text { satisfactory } \\
C=\text { poor }\end{array} \\
\text { Record rating on Evaluation } \\
\text { Criteria Worksheet }\end{array}$} \\
\hline & $\begin{array}{l}\text { Describe the corrective actions taken to achieve the } \\
\text { following objectives: }\end{array}$ & A & $\mathrm{B}$ & $\mathrm{C}$ \\
\hline$\bullet$ & $\begin{array}{l}\text { Verify the accuracy of the information to be communicated. } \\
(2.4)\end{array}$ & A & B & $\mathrm{C}$ \\
\hline$\cdot$ & $\begin{array}{l}\text { Ensure that the level of detail in messages is sufficient for } \\
\text { and tailored to the receiver's information needs. (2.5) }\end{array}$ & A & B & $\mathrm{C}$ \\
\hline - & Define vocabulary requirements. (2.6) & A & B & $\mathrm{C}$ \\
\hline & $\begin{array}{l}\text { Define methods for identifying equipment and systems. } \\
(2.7)\end{array}$ & A & B & $\mathrm{C}$ \\
\hline & $\begin{array}{l}\text { Define methods for identifying personnel involved in verbal } \\
\text { communications. }(2.8)\end{array}$ & A & B & $\mathrm{C}$ \\
\hline$\bullet$ & $\begin{array}{l}\text { Define methods for ensuring that senders and receivers } \\
\text { understand the communication requirements of a task before } \\
\text { it is performed. ( } 2.9)\end{array}$ & A & B & $\mathrm{C}$ \\
\hline
\end{tabular}




\begin{tabular}{|c|c|c|c|}
\hline \multicolumn{4}{|l|}{ 4.2 Development of Corrective Action Interview Protocol } \\
\hline $\begin{array}{l}\text { Date: } \\
\text { Interviewee: } \\
\text { Interviewer: }\end{array}$ & \multicolumn{3}{|c|}{$\begin{array}{l}\text { Circle rating on } \\
\qquad \begin{array}{l}A=\text { excellent } \\
B=\text { satisfactory } \\
C=\text { poor }\end{array} \\
\text { Record rating on Evaluation } \\
\text { Criteria Worksheet }\end{array}$} \\
\hline $\begin{array}{l}\text { Define methods for receivers to verify message receipt and } \\
\text { understanding, and to question conflicting or incomplete } \\
\text { messages. }(2.10) \\
\text { - Ensure that receivers will seek messages that were expected } \\
\text { but were not received. (2.11) }\end{array}$ & $\mathrm{A}$ & B & $\mathrm{C}$ \\
\hline
\end{tabular}




\subsection{Corrective Action Implementation and Effectiveness Interview Protocol}

\begin{tabular}{|c|c|c|c|}
\hline $\begin{array}{l}\text { Date: } \\
\text { Interviewee: } \\
\text { Interviewer: }\end{array}$ & \multicolumn{3}{|c|}{$\begin{array}{l}\text { Circle rating on } \\
\qquad \begin{array}{l}\text { A }=\text { excellent } \\
B=\text { satisfactory } \\
\text { C }=\text { poor }\end{array} \\
\text { Record rating on Evaluation } \\
\text { Criteria Worksheet }\end{array}$} \\
\hline $\begin{array}{l}\text { (1) What measurable objectives are to be achieved by } \\
\text { implementing corrective actions? }\end{array}$ & A & B & $\mathrm{C}$ \\
\hline $\begin{array}{l}\text { (2) Describe the evaluation criteria for determining that } \\
\text { objectives and desired conditions of the corrective actions } \\
\text { have been achieved. (3.2) }\end{array}$ & A & B & $\mathrm{C}$ \\
\hline $\begin{array}{l}\text { (3) How will the effectiveness of the corrective actions be } \\
\text { monitored? (3.3) }\end{array}$ & A & B & $\mathrm{C}$ \\
\hline $\begin{array}{l}\text { (4) Discuss whether corrective actions were reviewed before } \\
\text { implementation to ensure that they do not cause unintended } \\
\text { negative consequences. (3.4) }\end{array}$ & A & B & $\mathrm{C}$ \\
\hline
\end{tabular}




\section{COMMUNICATIONS OBSERVATION PROTOCOL}

The observation protocol focuses on communication-related behaviors in the control room; however, this protocol could be revised to cover in-plant or other areas. The protocol can also be used to rate licensee performance in selected behaviors related to implementation of actions. The protocol is divided into the following four areas:

5.1 Communication of Equipment Changes to Shift Personnel

5.2 Timely Communication to Shift Management Concerning Abnormal Conditions and Panel Manipulations

5.3 Use of Uniform Communication Techniques

5.4 Maintenance of Accurate and Timely Logs that Reflect Plant Activities and Status

Instructions:

It is not likely that NRC personnel will observe all of the items in this protocol.

However, for the relevant items, rate as either $\mathrm{A}, \mathrm{B}$, or $\mathrm{C}$, as defined in the rating scale below. The number in parentheses following the items corresponds to the criteria in the Evaluation Criteria Worksheet. Record the ratings on that worksheet.

Rating Scale:

A - Consistently The behavior is always done and the quality always exceeds minimum standards.

B - Generally The behavior is observed but is not being done consistently, or it is consistently done but the quality does not always meet minimum standards.

C - Erratically The behavior is not observed at all, or it is observed but does not meet minimum standards: 


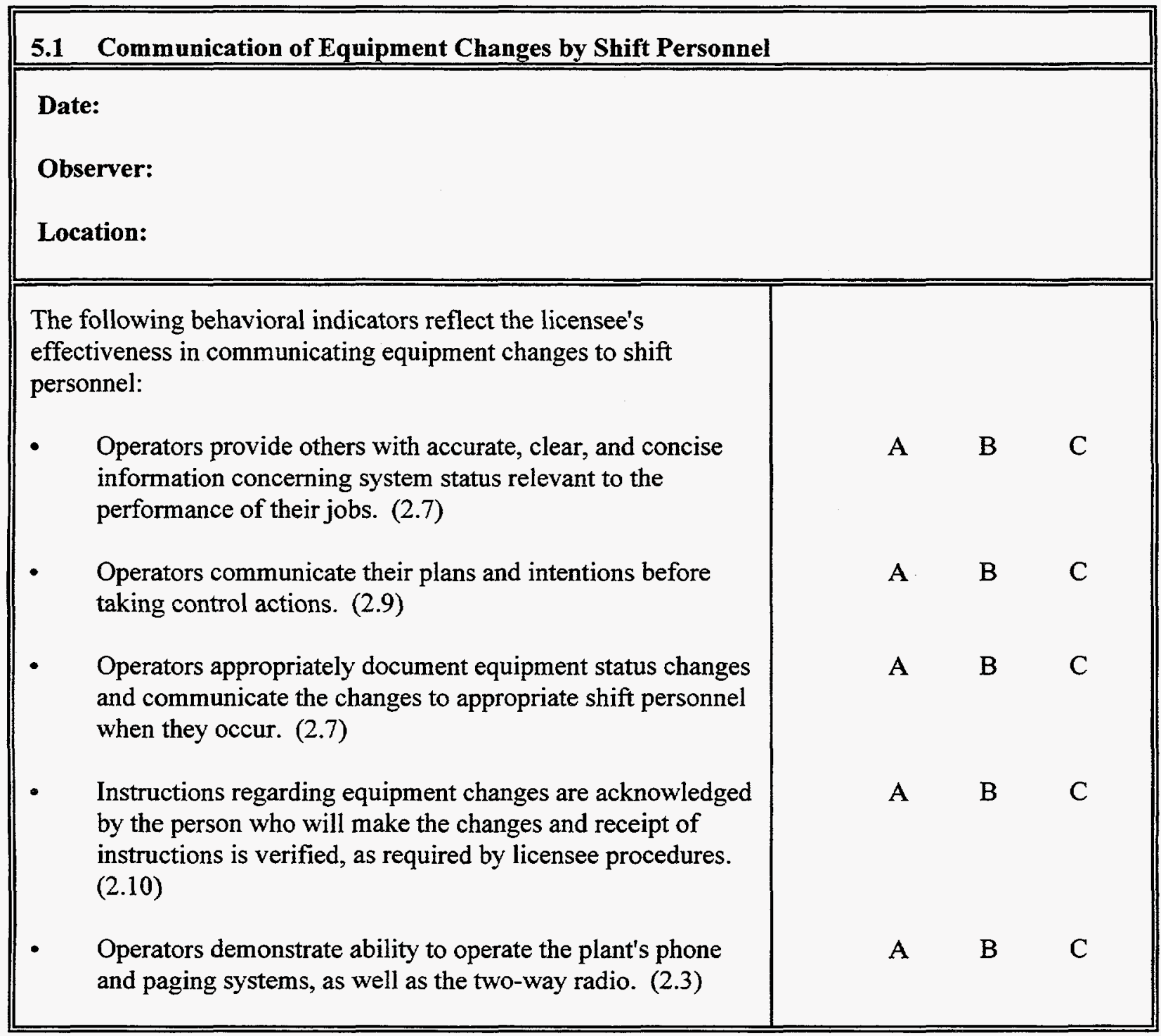




\subsection{Timely Communication to Shift Management Concerning Abnormal Conditions and Panel Manipulations}

Date:

Observer:

\section{Location:}

The following behavioral indicators reflect the licensee's

effectiveness in promptly informing shift management of abnormal conditions and panel manipulations:

- Plant management is informed of abnormal conditions as required by plant policies. (2.11)

- $\quad$ Problems are documented in accordance with site problem reporting procedures. (3.2)

- Communication between workers and first line supervisors, as well as interdepartmental communications, are appropriate and follow any plant-specific communication procedures. (2.4)

- Operators inform unit supervisors of any changes in the status of plant equipment and systems. (2.7)

A B C

A $\quad$ B $\quad$ C

A $\quad$ B $\quad$ C

A $\quad$ B $\quad$ C 


\subsection{Use of Uniform Communication Techniques}

Uniform verbal communication techniques are used as defined by the plant's policy on verbal communications, or during the following situations::

- when communicating with members of other departments or work units

- when communication is not face-to-face

- during pre-job and pre-evolution briefings

- when planning for potentially risky activities

- when performing potentially risky activities

- when conducting time-critical tasks or during periods of high workload 


\subsection{A Use of Uniform Communication Techniques: The Sender}

The volume of speech is consistently loud enough to be heard over the ambient noise levels. (2.6)

Senders enunciate clearly and speak at a speed that makes the messages intelligible. (2.6)

Uniform, common terminology is consistently used (e.g., no slang). (2.3)

A B C

Messages are concise and task-related. (2.6)

Words are avoided that can be easily confused with others and "misheard" (e.g., "lower" is used instead of "decrease," which can be misheard as "increase"). (2.6)

The phonetic alphabet is used to communicate letters and uncommon or unfamiliar acronyms and abbreviations (e.g., alpha for A, bravo for B). (2.6)

System/component identification information is stated completely (e.g., noun name, alphanumeric identifier, unit or train designator, specific location in the plant).

When communicating over the public address system or radios, or over physical distance, personnel identify themselves by name, job role (e.g., reactor operator, auxiliary operator, electrical maintenance technician), and plant location. (2.8)

Senders consistently ask for confirmation of message receipt before terminating the communication. (2.10)

Senders verify or correct the receiver's understanding of the message. (2.10)

Senders consistently ask for questions before terminating the communication. (2.10)

When asked questions, senders respond in a timely and professional manner. (2.9)

When asked questions, senders respond completely (e.g., "Yes, the residual heat removal [or RHR] pumps are running" rather than "Yes" or "Yes, they are running.") (2.5) 


\subsection{B Use of Uniform Communication Techniques: The Receiver}

- The intended receivers of a message attend to it (e.g., establish eye contact, if physically co-located). (2.8)

A $B \quad$ C

A $B \quad$ C

- If distracted as a result of high workload or involvement in time-critical tasks, intended receivers ask the sender to delay the communication. (2.8)

- If given a command to act, receivers verify that the sender was authorized to issue the command. (2.9)

- If physically separated from the sender, receivers identify themselves by name, job role, and plant location. (2.8)

- Receivers show a critical listening attitude by identifying inconsistencies, ambiguities, disagreements, or incomplete information and questioning them before acting on the communication. (2.9)

- Receivers seek information when an expected communication does not occur. (2.11)

- Receivers confirm message receipt and understanding by completely repeating what was heard. (2.10)

A B C

A $B \quad$ C

A $B \quad$ C

A $B \quad$ C

A $B \quad$ C 


\subsection{Maintenance of Accurate and Timely Logs that Reflect Plant Activities and Status}

Written records of plant operations need to be carefully prepared and maintained in accordance with requirements for such records and in sufficient detail to provide a full understanding of operationally significant matters.

Review the major operating logs (control room, shift supervisor, operating orders, etc.). Assess the effectiveness of the communications provided by the logs. Determine whether the records are being maintained and reviewed as required by the licensee's administrative procedures.

Review the logs and records for the following purposes:

- Obtain information.

- Detect significant changes and trends in performance.

- Detect possible conflicts with technical specifications or inadequate safety practices, including indications that prerequisites have not been satisfied before startup, shutdown, or mode changes. 


\subsection{Maintenance of Accurate and Timely Logs that Reflect Plant Activities and Status}

- Logbook entries are neat and legible, and no vacant lines are left between entries.

- $\quad$ Errors are corrected by a single line drawn through the entry and initialed.

- Logbook entries reflect plant status and abnormal system or equipment alignments.

- Staff personnel record significant operational events, unusual parameters, and alterations to safety related system alignments.

- Logbook entries are made on a real-time basis (rather than keeping an unofficial "pencil log" and making official entries at the end of the shift).

- Periodic reviews of logbooks are completed by staff personnel, and the pages are initialed and dated in accordance with plant procedures.

- Staff personnel promptly record log book entries regarding entry into or exit from Technical Specification limiting conditions for operation (LCOs), as required by plant procedures.

- Logbooks contain numbers and classifications of operations personnel on duty on each shift to ensure compliance with Technical Specification staffing requirements.
A $B \quad$ C

A $B \quad$ C

A B C

A $B \quad$ C

A B C

A $B \quad$ C

A B C

A B C 


\section{EVALUATION CRITERIA WORKSHEET}

\section{Instructions}

Complete this Evaluation Criteria Worksheet by circling A (excellent), B (satisfactory), or C (poor) for each of the criterion under each column (document review, interview, and observation). 


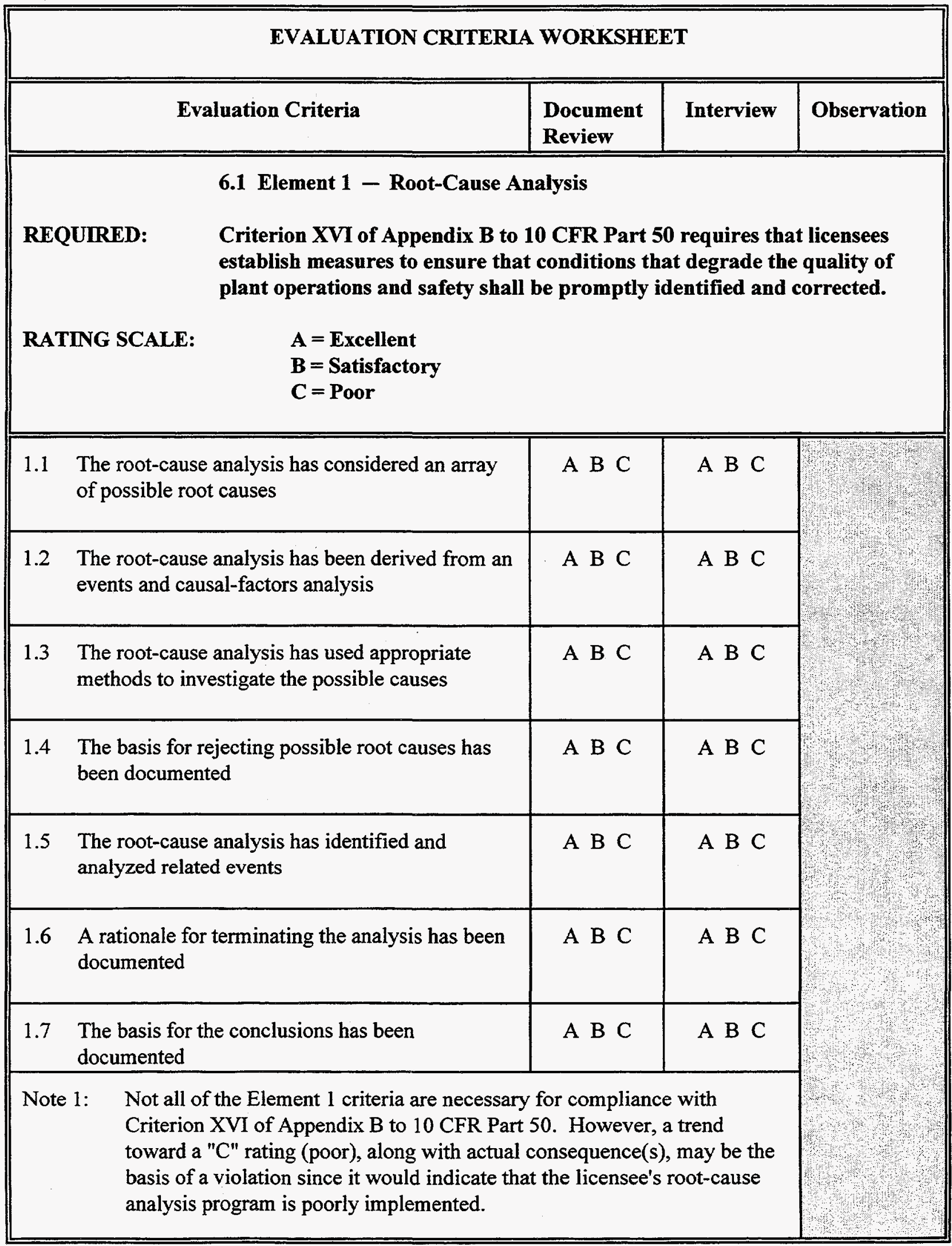




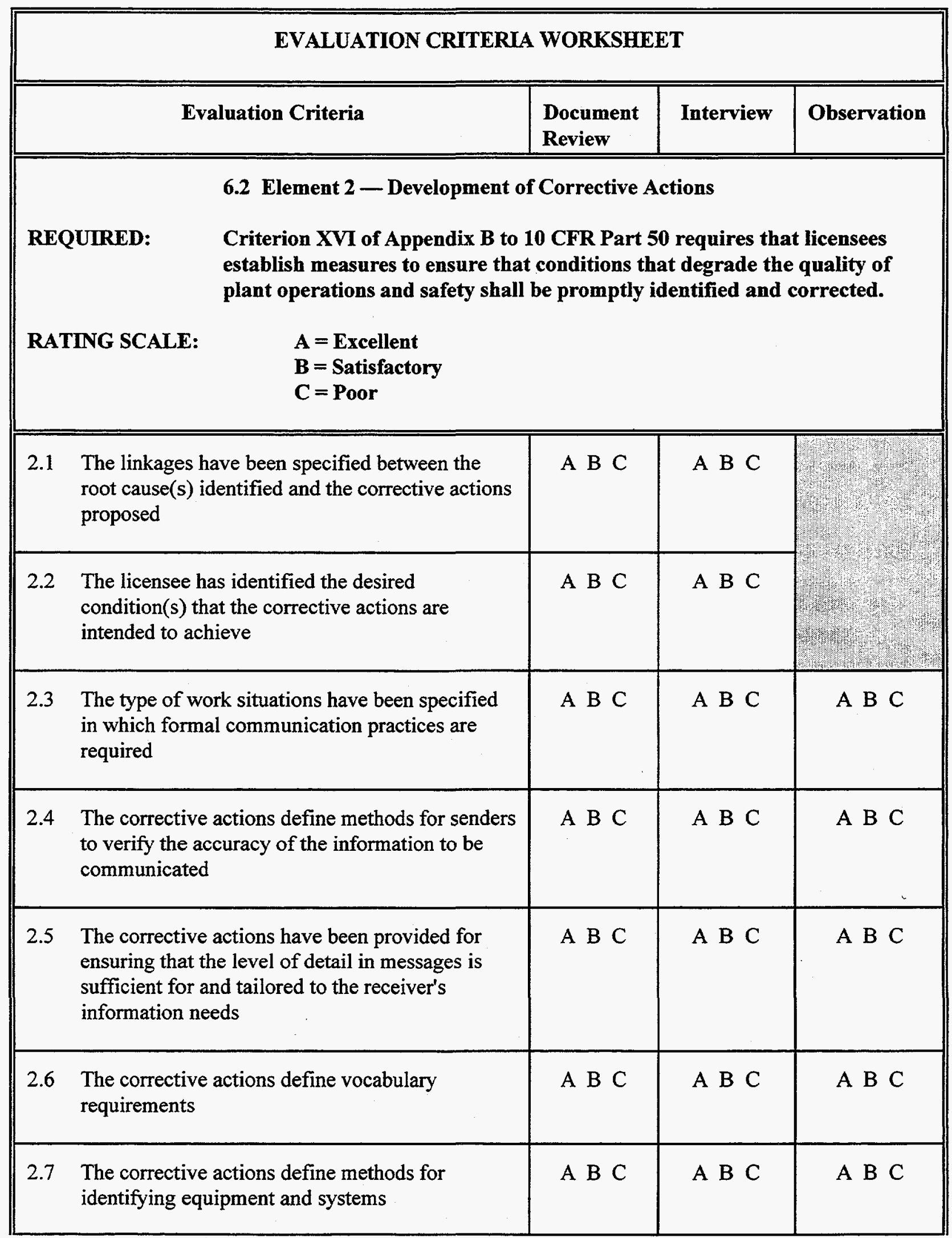




\begin{tabular}{|c|c|c|c|c|}
\hline \multicolumn{5}{|c|}{ EVALUATION CRITERIA WORKSHEET } \\
\hline & Evaluation Criteria & $\begin{array}{l}\text { Document } \\
\text { Review }\end{array}$ & Interview & Observation \\
\hline 2.8 & $\begin{array}{l}\text { The corrective actions define methods for } \\
\text { identifying the personnel involved in verbal } \\
\text { communications }\end{array}$ & A B C & A B C & A B C \\
\hline 2.9 & $\begin{array}{l}\text { The corrective actions define methods for } \\
\text { ensuring that senders and receivers understand } \\
\text { the communication requirements of a task before } \\
\text { task performance }\end{array}$ & A B C & A B C & A B C \\
\hline 2.10 & $\begin{array}{l}\text { The corrective actions define methods for } \\
\text { receivers to verify message receipt, to verify } \\
\text { message understanding, and to question } \\
\text { conflicting or incomplete messages }\end{array}$ & A B C & A B C & A B C \\
\hline 2.11 & $\begin{array}{l}\text { The corrective actions ensure that receivers will } \\
\text { seek messages that were expected but were not } \\
\text { received }\end{array}$ & $\mathrm{A} B \mathrm{C}$ & A B C & A B C \\
\hline \multicolumn{5}{|c|}{$\begin{array}{l}\text { Note 2: Not all of the Element } 2 \text { criteria are necessary for compliance with Criterion XVI of } \\
\text { Appendix B to } 10 \text { CFR Part } 50 \text {. However, a trend toward a "C" rating (poor), along with } \\
\text { actual consequence(s), may be the basis of a violation since it would indicate that the } \\
\text { licensee's corrective action program is poorly implemented. }\end{array}$} \\
\hline
\end{tabular}




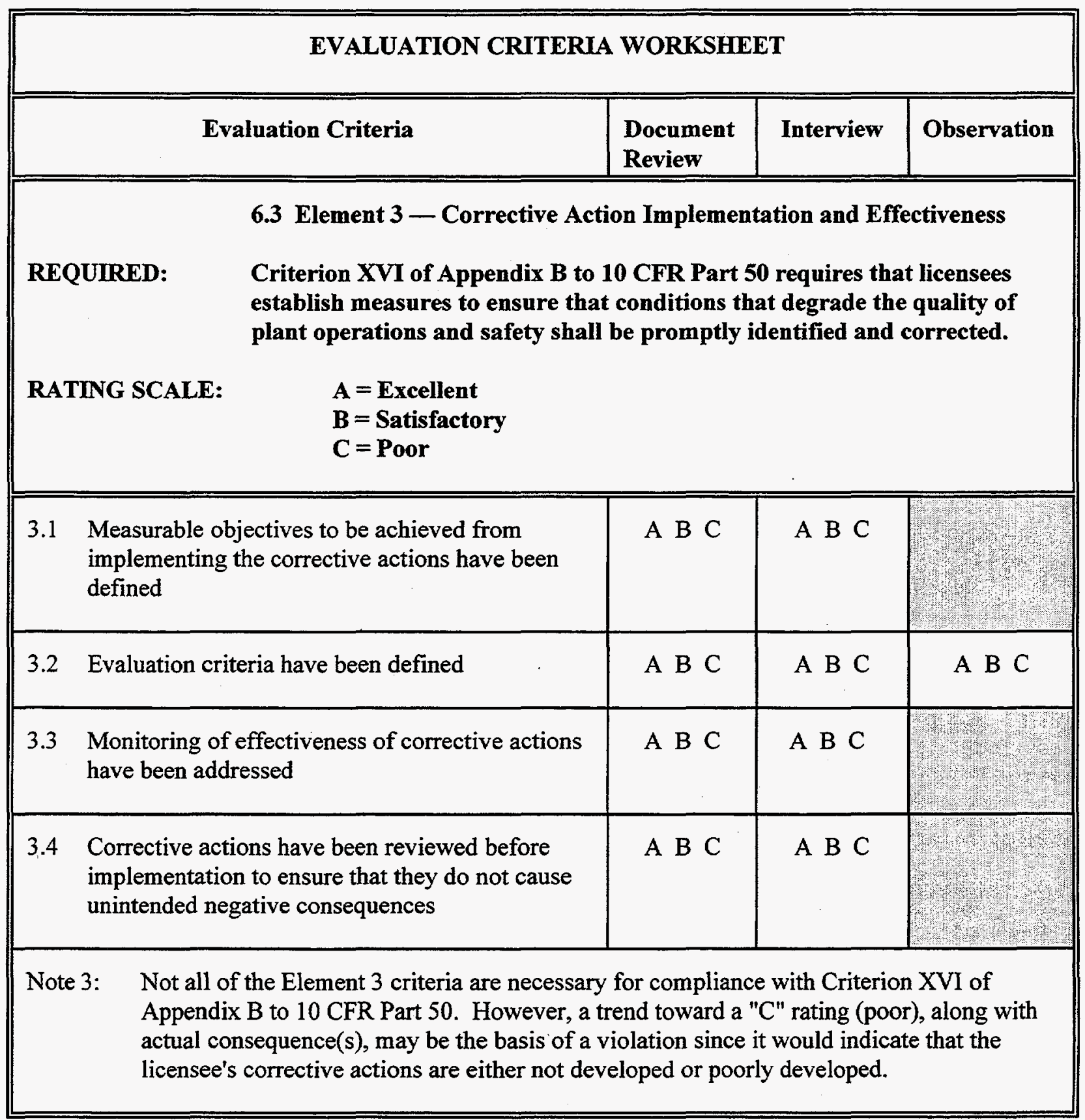




\section{SUMMARY RATING WORKSHEET}

The Summary Rating Worksheet provided in this section can be used to summarize the results of the evaluation for Elements 1, 2, and 3 (i.e., the root-cause analysis, development of corrective actions, and implementation and effectiveness of the corrective actions), as determined using the Evaluation Criteria Worksheet in Section 6. The summary of information from these evaluations makes trends visible and can be useful when presenting review findings. The summary can also be used to illustrate findings from the review of a single program (e.g., root-cause analysis) or it can be used to show findings about the relationship between programs (e.g., corrective actions and their implementation and effectiveness).

The Summary Rating Worksheet should be used as follows:

(1) Using the Evaluation Criteria Worksheet, determine a summary rating (A, B, or C) for each criterion related to each of the three elements. Each summary rating should be associated with a color (i.e., $\mathrm{A}=$ green, $\mathrm{B}=$ yellow, $\mathrm{C}=$ red). On the Summary Rating Worksheet, highlight each criterion with the appropriate color.

Example: The Evaluation Criteria Worksheet shows that Criterion 2.3 has an " $\mathrm{A}$ " rating for "document review," a " $\mathrm{B}$ " rating for "interview," and a " $\mathrm{B}$ " rating for "observation." Hence, the overall rating for Criterion 2.3 was determined to be "B." Note that a " $\mathrm{B}$ " rating is represented by the color "yellow." On the Summary Rating Worksheet, highlight Criterion 2.3 in yellow.

(2) Considering the highlighted ratings for all of the criteria related to a given element, determine the overall ratings for Elements 1, 2, and 3, and circle the appropriate performance level (i.e., excellent, satisfactory, or poor) for each element. 


\section{SUMMARY RATING WORKSHEET}

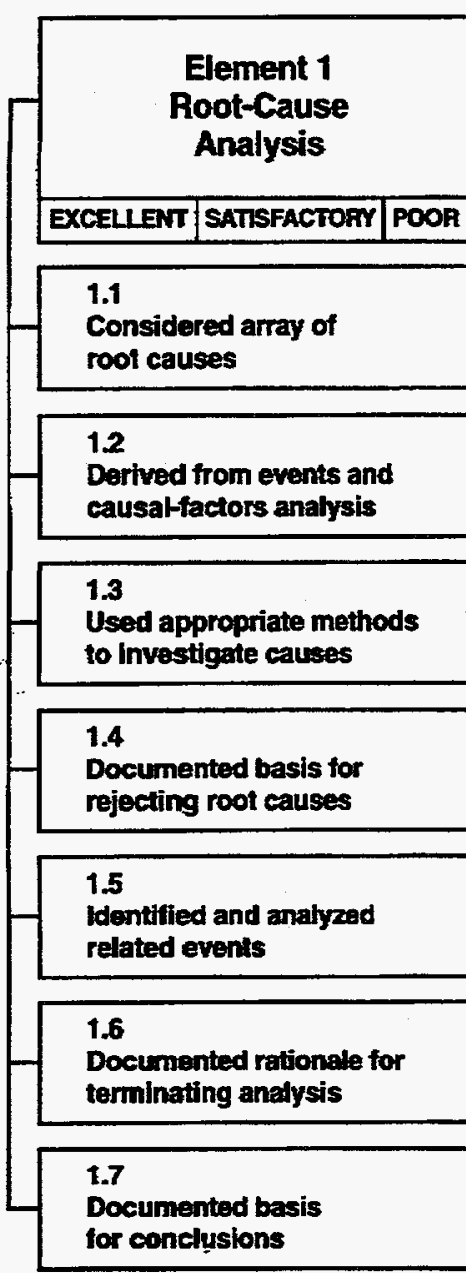

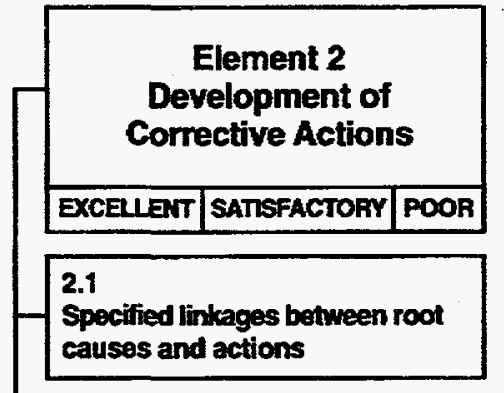

2.2

Identified conditions corrective actions are intended to achieve

\section{3}

Specified work sltuations

that require formal

communications

24

Defined methods to verity

information aceuracy

2.5

Provided actions to ensure

sufficient level of detail tailored

to receiver's information needs

2.6

Defined vocabulary requilements

27

Defined methods for identirying of equipment and systems

\section{8}

Defined methods for identifying personnel involved in verbal communications

29

Defined mothods for ensuring communications requirements are understood before task performance

2.10

Defined methods to verily message receipt and understanding, and to question conflicting or incomplete messages

\subsection{1}

Ensured that receivers will seek expected messages

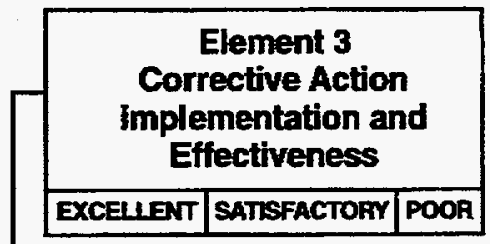

3.1

Defined measurable objectives

3.2

Defined evaluation criteria

\section{3}

Addressed continued monitoring of corrective action effectiveness

3.4

Reviewed corrective actions to prevent potential negative consequences 


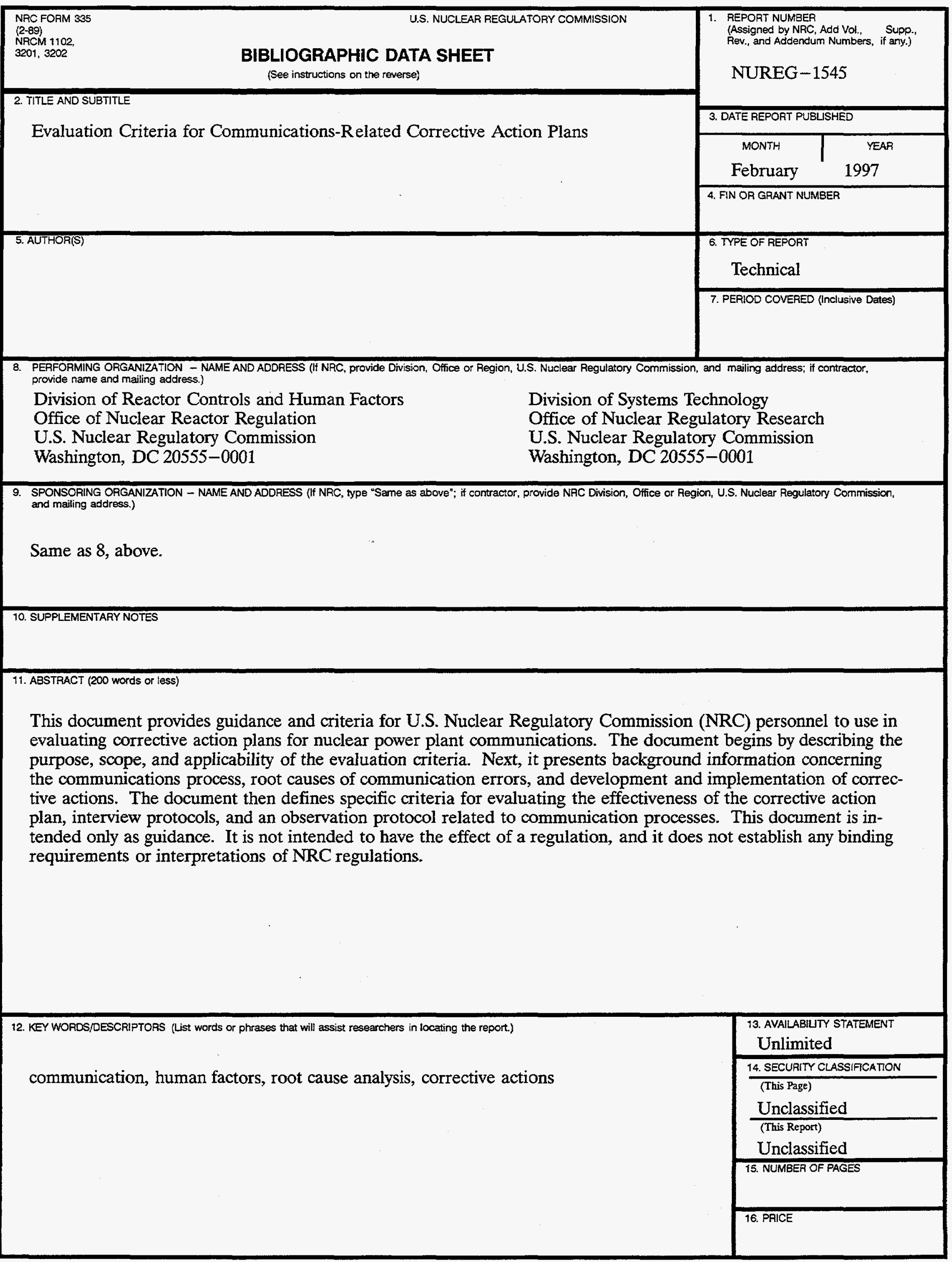

